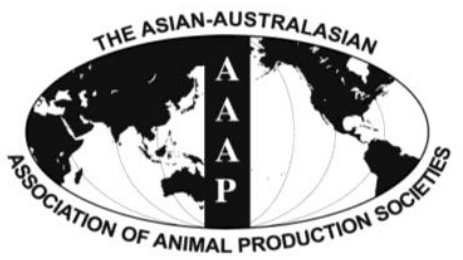

Asian-Aust. J. Anim. Sci.

Vol. 25, No. $8: 1083$ - 1088

August 2012

www.ajas.info

http://dx.doi.org/10.5713/ajas.2012.12127

\title{
Proteome Analysis of Bovine Longissimus dorsi Muscle Associated with the Marbling Score
}

\author{
Y. N. Shen, S. H. Kim ${ }^{1}$, D. H. Yoon ${ }^{2}$, H. G. Lee ${ }^{3}$, H. S. Kang ${ }^{4}$ and K. S. Seo ${ }^{4} *$ \\ Division of Radiation Cancer Research, Korea Institute of Radiological and Medical Sciences, Seoul 139-706, Korea
}

\begin{abstract}
The breeding value of marbling score in skeletal muscle is an important factor for evaluating beef quality. In the present study, we investigated proteins associated with the breeding value of the marbling score for bovine sirloin to select potential biomarkers to improve meat quality through comparative proteomic analysis. Proteins isolated from muscle were separated by two-dimensional gel electrophoresis. After analyzing images of the stained gel, seven protein spots for the high marbling score group were identified corresponding to changes in expression that were at least two-fold compared to the low marbling score group. Four spots with increased intensities in the high marbling score group were identified as phosphoglycerate kinase 1, triosephophate isomerase, acidic ribosomal phosphoprotein PO, and capping protein (actin filament) Z-line alpha 2. Spots with decreased intensities in the high marbling score group compared to the low score group were identified as 14-3-3 epsilon, carbonic anhydrase II, and myosin light chain 1. Expression of myosin light chain 1 and carbonic anhydrase 2 was confirmed by Western blotting. Taken together, these data could help improve the economic performance of cattle and provide useful information about the underlying the function of bovine skeletal muscle. (Key Words: Sirloin, Skeletal Muscle, Marbling Score, Proteomics, Cattle)
\end{abstract}

\section{INTRODUCTION}

Skeletal muscles are the main tissue involved in glucose utilization and are highly sensitive to insulin (Zierath, 1995). The importance of longissimus dorsi muscle (sirloin) development in beef production is well established. Sirloin contains intramuscular fat which is an important factor for evaluating beef yield and quality. Marbling is defined as the ratio of intramuscular fat contents to muscle mass in a cross-section of longissimus dorsi muscle (Cameron et al., 1994). Increases in marbling score (MS) are associated with improved beef quality by affecting the taste and tenderness of the meat (Crouse et al., 1984). Marbling is a prime factor in the South Korean beef industry. Throughout the quality grading system, animals with high MS are assigned a higher

\footnotetext{
* Corresponding Author: K. S. Seo. Tel: +82-61-750-3232, Fax:+82-61-750-3232, E-mail: sks@ scnu.kr

${ }^{1}$ Department of Biology, Kyung Hee University, 26 Dongdaemungu, Seoul, Korea.

${ }^{2}$ Department of Animal Science, Kyungpook National University, 386 Gajang-dong Sangju, Kyungpuk, 742-711, Korea.

3 Department of Bio-Resources, Natural Resource and Life Science, Busan National University, Miryang, Korea.

4 Department of Animal Science and Technology, Sunchon National University, Sunchon, Korea.

Submitted Mar. 7, 2012; Accepted Apr. 9, 2012; Revised Apr. 24, 2012
}

quality grade than animals with low MS (Lee et al., 2004; Moon et al., 2006). Hypertrophy in skeletal muscle is defined as an increase of muscle mass, and is characterized by increased protein mass per fiber resulting from a net increase of protein synthesis relative to breakdown. Moreover, hypertrophy in skeletal muscle could be related to marbling and affect beef production (Nader et al., 2002; Glass, 2003).

Proteomics is a novel area of research that involves the global analysis of cellular proteins using numerous technologies such as 2-dimensional gel electrophoresis (2-DE), mass spectrometry, and bioinformatics. Although the proteome profile of bovine skeletal muscle was reported (Bouley et al., 2005; Chaze et al., 2006), there is no data available for the proteome associated with economic performance. In our previous study, we identified proteins specifically expressed in bovine sirloin compared to rump tissue (Kim et al., 2006). Therefore, we performed the current study to identify proteins associated with the breeding value of MS for bovine sirloin to identify potential bioregulators using a comparative proteomic analysis.

\section{MATERIALS AND METHODS}

\section{Sample preparation}

Hanwoo cattles were slaughtered at 24 months of age. 
Bovine longissimus dorsi isolated from the 13th rib were frozen immediately after dissection and stored at $-196^{\circ} \mathrm{C}$ until protein analysis. To isolate protein extracts, bovine longissmus dorsi were weighed and thawed in buffer (7 M urea, $2 \mathrm{M}$ thiourea, 4\% CHAPS, and $10 \mathrm{mM}$ DTT). Homogenization $(30 \mathrm{mg} / \mathrm{ml})$ was performed at room temperature with a rotor blade homogenizer followed by centrifugation at $15,000 \mathrm{rpm}$ at $4^{\circ} \mathrm{C}$ for $30 \mathrm{~min}$. The supernatant was aliquoted and stored at $-80^{\circ} \mathrm{C}$ until the 2-DE analysis was performed.

\section{Two-dimensional polyacrylamide gel electrophoresis}

Protein extracts $(100 \mu \mathrm{g})$ were applied to Immobiline $\mathrm{T}^{\mathrm{TM}}$ Dry strips ( $\mathrm{pH} 3$ to $10,18 \mathrm{~cm}$; Amersham Biosciences, Gjettum, Sweden). Isoelectrofocusing was conducted using Pharmalytes ( $\mathrm{pH} 3$ to 10) for a 12-h rehydration period, $1 \mathrm{~h}$ in $500 \mathrm{~V}$ gradient, $1 \mathrm{~h}$ in a $8,000 \mathrm{~V}$ gradient, and $13 \mathrm{~h}$ at a $8,000-\mathrm{V}$ steady-state level. After isoelectrofocusing in the first dimension, strips were incubated with gentle shaking in an equilibration buffer (50 mM Tris- $\mathrm{HCl}, \mathrm{pH} 8.8 ; 6 \mathrm{M}$ urea, $30 \%$ glycerol, $2 \%$ SDS, and a trace of bromophenol blue) containing $1 \%$ DTT for $15 \mathrm{~min}$, and $2.5 \%$ iodoacetamide for $15 \mathrm{~min}$. For the second dimension, the strips were transferred to the tops of $12.5 \%$ polyacrylamide gels containing SDS. Proteins were separated for $12 \mathrm{~h}$. After fixation, proteins were detected using a silver staining kit.

\section{Image analysis}

Gels were scanned using an ImageScanner flatbed scanner. Protein spots were analyzed using ImageMaster 2-DE Elite software (Amersham Biosciences, Gjettum, Sweden). Spots were detected and quantified automatically. All master images were obtained from 2-DE analysis.

\section{Protein identification by ESI-Q-TOF-MS/MS}

Proteins were subjected to in-gel trypsin digestion. Excised gel spots were destained and incubated with 200 $\mathrm{mM}$ ammonium bicarbonate for $20 \mathrm{~min}$. The gel pieces were dehydrated in acetonitrile and dried in a vacuum centrifuge. The dried gel pieces were rehydrated in $50 \mathrm{mM}$ ammonium bicarbonate containing $0.2 \mu \mathrm{g}$ modified trypsin (Promega, Madison, WI, USA) for $45 \mathrm{~min}$ on ice. After removing the solution, $50 \mathrm{mM}$ ammonium bicarbonate was added. A column containing of Poros reverse phase R2 material (20 to $30-\mu \mathrm{m}$ bead size, PerSeptive Biosystems, Norwlk, CT, USA) was packed in a constricted GELoader tip (Eppendorf, Hamburg, Germany). Thirty L of the peptide mixture from the digestion supernatant were diluted in $5 \%$ formic acid, loaded onto the column, and washed with $5 \%$ formic acid. For MS/MS analyses, peptides were eluted with $50 \%$ methanol, $49 \% \mathrm{H}_{2} \mathrm{O}$, and $1 \%$ formic acid directly into a pre-coated borosilicate nanoelectrospray needle (Micromass, Manchester, UK). MS/MS analysis of peptides generated by in-gel digestion was performed by nano-ESI on a Q-TOF mass spectrometer (Micromass, Manchester, UK). Product ions were analyzed using an orthogonal TOF analyzer, fitted with a reflector, microchannel plate detector and time-to-digital converter. The data were processed using a Mass Lynx Windows NT PC system (Micromass, Manchester, UK). To identify the proteins, all MS/MS spectra recorded for tryptic peptides recovered from the gel spots were used for searches of protein sequences from the NCBInr databases using the MASCOT program.

\section{Western blotting}

Protein extracts $(30 \mu \mathrm{g})$ were separated by SDS-PAGE and transferred onto a nitrocellulose membrane in $25 \mathrm{mM}$ Tris-HCl buffer ( $\mathrm{pH} 8.8$ ) containing $0.19 \mathrm{M}$ glycine, $0.1 \%$ SDS, and $20 \%$ methanol at $120 \mathrm{~mA}$ for $1 \mathrm{~h}$. The membrane was probed with antibodies specific for myosin light chain 1 (Abcam, Cambridge, UK) and carbonic anhydrase 2 (Novus Biologicals, Littleton, CO, USA) at a 1:500 diultion for $1 \mathrm{~h}$. The blot was then incubated with horseradish peroxidase-labeled anti-rabbit $\operatorname{IgG}$ serum for $1 \mathrm{~h}$, and antibody binding was visualized using a SuperSignal enhanced chemiluminescence kit from Amersham Biosciences.

\section{Statistic analysis}

Data for a total of 146 animals from progeny tests at the National Institute of Animal Science, South Korea were used. The animals were ranked based on the MS and divided into two groups: a high MS group (0.4 to 1.5$)$ and low MS group (-0.8 to -0.55$)$. The MS was determined according to the ratio of intramuscular fat content to muscle mass. Differences between these two groups were analyzed with a t-test. A simple correlation analysis was conducted to assess the association between spot intensity and breeding value.

An animal model with BLUP as a mixed linear model was used to estimate the individual breeding values. The animal model used for the analysis was:

$$
Y_{i j k l}=\mu_{i}+Y S_{i j}+L_{i k}+A_{i j k l}+b_{i} D_{i j k l}+e_{i j k l}
$$

in which $Y_{i j k l}$ is observation ${ }_{i j k l}$ for the traits, $\mu_{i}$ is the population mean for the $i$ th trait, $Y S_{i j}$ is the fixed effect of $j$ th year-season for the $i$ th trait, $L_{i k}$ is the fixed effect of $k$ th location of birth for the $i$ th trait, $A_{i j k l}$ is the random additive genetic effect of individual for the $i$ th trait, $b_{i}$ is the linear regression coefficient for the $i$ th trait, $D_{i j k l}$ is the age at slaughter on the day for the $i$ th carcass trait, and $e_{i j k l}$ is the random residual associated with observation $i j k l$. 


\section{RESULTS}

\section{Proteome analysis of bovine sirloin}

In the present study, we separated bovine samples according to the estimated breeding value of MS. According to the South Korean breeding system established by the National Institute of Animal Science, breeding values for MS between 0.4 and 1.5 were assigned to the high MS group whereas values between -0.8 and -0.55 were assigned to the low MS group (Figure 1). Twenty cows each were placed in the high and low MS groups. Proteins extracted from bovine longissimus dorsi muscle were separated on a 2-DE gel for proteomic analysis. A total of 300 spots were detected in the gel and spot intensities were compared (Figure 1A). The image analysis identified seven spots corresponding to differently expressed proteins (Figure 1B). Among these, four protein spots corresponded to proteins highly expressed in the high MS group compared to the low

(A)

High MS group

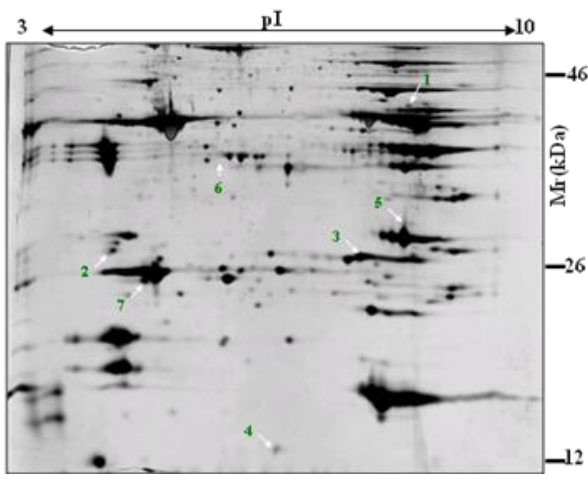

Low MS group

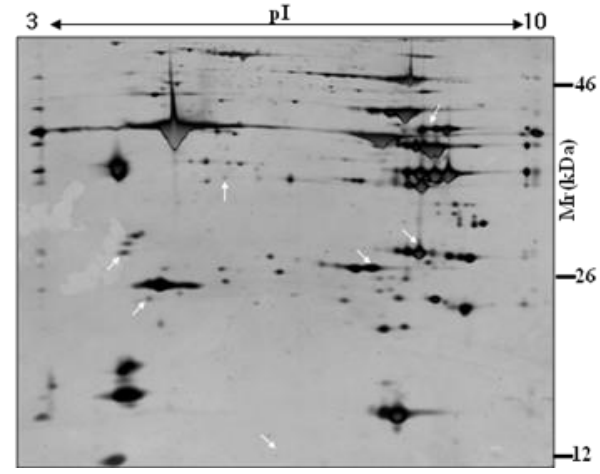

(B)
Spot No.
1
2
3
4
5
6
7
High MS group
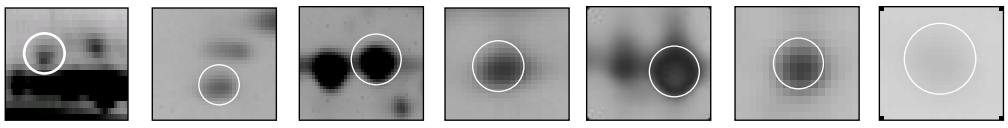
Low MS group
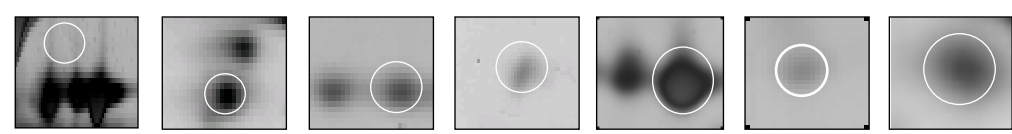

(C)
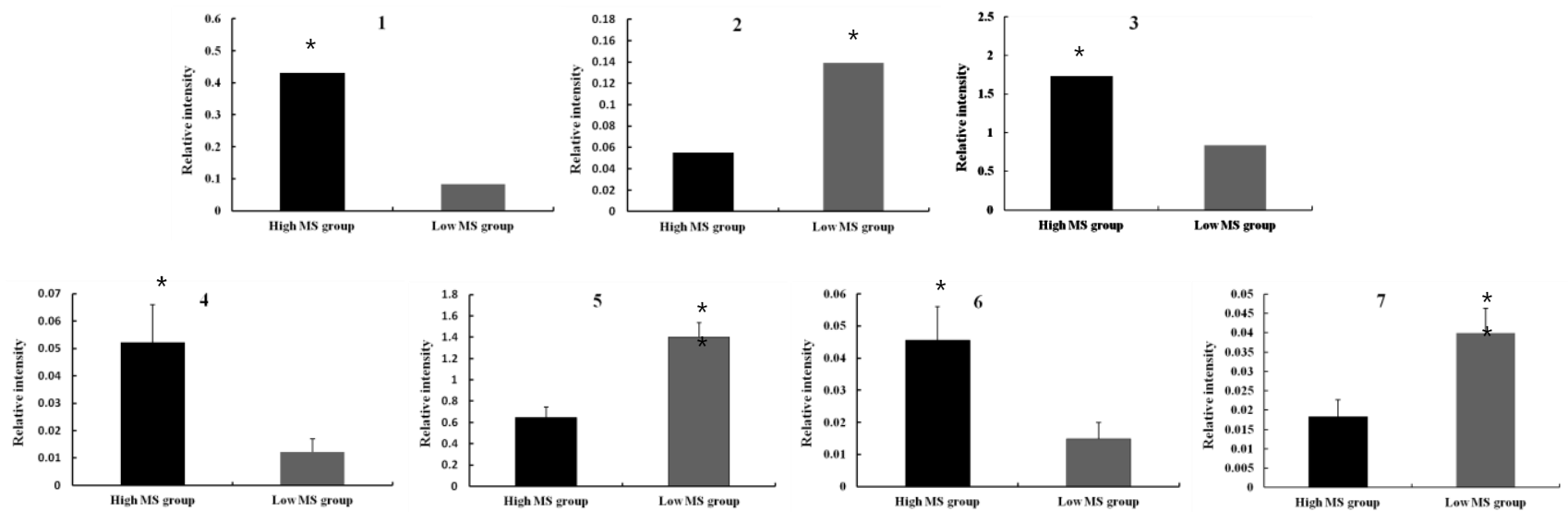

Figure 1. 2-DE images of bovine longissimus dorsi muscle. (A) Protein patterns of bovine sirloin taken from high and low marbling score (MS) groups. One hundred $\mu \mathrm{g}$ of protein extracts were separated by 2-DE and stained with a silver staining kit. Spots corresponding to differently expressed proteins are indicated by arrows. (B) The magnified fields of the 2-DE images showing differences in protein expression patterns between the high and low MS groups. (C) Quantification of differentially expressed proteins in bovine muscle. Student's $t$-test was performed to compare protein expression patterns between the high and low MS groups $(\mathrm{n}=20$, $* \mathrm{p}<0.05 ; * * \mathrm{p}<0.01)$. 
MS group. The intensity of spot no. 1 was increased 4-times in the high MS group compared to the low MS group. The intensity of spot no. 3 in high MS group was 2-times higher than that of the low MS group $(\mathrm{p}<0.01)$. In contrast, the intensity of spot no. 2 decreased in the high MS group compared to the low MS group ( $\mathrm{p}<0.05$; Figure 1C). Our results suggest that these proteins in bovine muscle are highly related to MS.

\section{Identification of differentially expressed proteins by ESI-Q-TOF MS/MS}

Selected protein spots were excised from the silverstained gels and subjected to in-gel trypsin digestion. The extracted peptides were analyzed by nano-ESI on a Q-TOF mass spectrometer. Data for the analyzed protein spots in bovine longissimus dorsi muscles are presented in Table 1. Four spots with increased intensities in the high MS group were identified as phosphoglycerate kinase 1, triosephophate isomerase, acidic ribosomal phosphoprotein $\mathrm{PO}$, and capping protein (actin filament) Z-line alpha 2 . The three spots with decreased intensities in the high MS groups were identified as 14-3-3 epsilon, carbonic anhydrase II, and myosin light chain 1 (slow-twitch muscle).

All seven spots we analyzed were also significantly correlated with the breeding value of MS. Highly expressed spots in the high MS group were positively correlated with the breeding value for MS. In contrast, proteins with low expression levels in high MS group were negatively associated with the breeding value of MS (Table 1).

In order to validate our proteomic data, we conducted a Western blot analysis for individual tissues from both groups. Since antibodies against myosin light chain 1 and carbonic anhydrase 2 were commercially available, expression patterns of these two proteins in bovine muscle were evaluated. As shown in Figure 2, the level of myosin light chain 1 (slow-twitch muscle) protein tended to decrease in the high MS group compared to the low MS group. Alternatively, expression of carbonic anhydrase 2 was reduced in high MS groups. These results suggest that myosin light chain 1 and carbonic anhydrase 2 may act as putative bioregulator proteins and help improve the MS of bovine sirloin.

\section{DISCUSSION}

The differential proteome analysis performed in this study showed that the expression of seven proteins in bovine longissimus dorsi quantitatively differed between the low and high MS groups. Spot no. 1, which increased in intensity in the high MS group, was identified as phosphoglycerate kinase (PGK). PGK is an enzyme in the glycolytic pathway that converts 3-phosphoglycerol phosphate into 3-phosphoglycerate. Another protein (spot no. 3) that decreased in expression in muscle tissues from the low MS group was triosephosphate isomerase (TIM). TIM catalyzes the fifth reaction of the glycolytic pathway, namely the interconversion of glyceraldehyde-3-phosphate and dihydroxyacetone phosphate, two ketose-aldose isomers (Rieder and Rose, 1959). These enzymes are involved in energy metabolism in skeletal muscle (Dubowitz et al., 1960). Phosphoglycerate kinase and TIM catalyze a key step in anaerobic ATP regeneration. Increased expression of glycolytic enzymes in tissues from the high MS group is strongly associated with increased intramuscular fat content (Larzul et al., 1997; Jeukendrup, 2002). Expression of the glycolytic enzyme triosephophate isomerase in muscle is also correlated with meat tenderness (Lametsch et al., 2003). These differences are associated with different mechanical properties that allow muscles to meet various functional demands.

Classification of muscle fibers into at least three types is based on contractile and/or metabolic properties (Cornforth et al., 1980; Kichofer et al., 2002). The basic classification system consists of slow-twitch oxidative (type I), fasttwitch oxidative glycolytic (type IIa), and fast-twitch glycolytic (type IIb) fiber types (Pearson and Young, 1989).

Table 1. Proteins identified in bovine longissimus dorsi muscle using ESI-Q-TOF MS/MS

\begin{tabular}{|c|c|c|c|c|c|c|}
\hline Spot no. & Protein name & NCBI accession no. & $\begin{array}{l}\text { Experimental } \\
\mathrm{pI} / \mathrm{Mr}(\mathrm{kDa})\end{array}$ & $\%$ coverage & $\begin{array}{l}\text { Theoretical } \\
\mathrm{pI} / \mathrm{Mr}(\mathrm{kDa})\end{array}$ & Correlation \\
\hline 1 & Phosphoglycerate kinase 1 & NP_001029471 & $8.64 / 44.9$ & 17 & $8.48 / 44.5$ & 0.561 \\
\hline 2 & 14-3-3 epsilon & NP_776916 & $4.57 / 27.3$ & 62 & $4.70 / 24.5$ & -0.715 \\
\hline 3 & Triosephosphate isomerase & NP_001013607 & $6.45 / 26.9$ & 11 & $6.45 / 26.7$ & 0.656 \\
\hline 4 & $\begin{array}{l}\text { Acidic ribosomal } \\
\text { phosphoprotein PO }\end{array}$ & BAC56548 & $6.06 / 13.3$ & 29 & $5.59 / 17.0$ & 0.610 \\
\hline 5 & Carbonic anhydrase II & NP_848667 & $7.71 / 29.6$ & 17 & $7.84 / 29.4$ & -0.478 \\
\hline 6 & $\begin{array}{c}\text { Capping protein } \\
\text { (actin filament) muscle, } \\
\text { Z-line alpha2 }\end{array}$ & NP_001013016 & $5.59 / 34.6$ & 40 & $5.57 / 33.0$ & 0.624 \\
\hline 7 & $\begin{array}{l}\text { Myosin light chain1 } \\
\text { slow-twitch muscle }\end{array}$ & P08590 & $4.71 / 25.8$ & 28 & $5.03 / 22.0$ & -0.473 \\
\hline
\end{tabular}

Correlation coefficient between the breeding value of MS and spot intensity. 


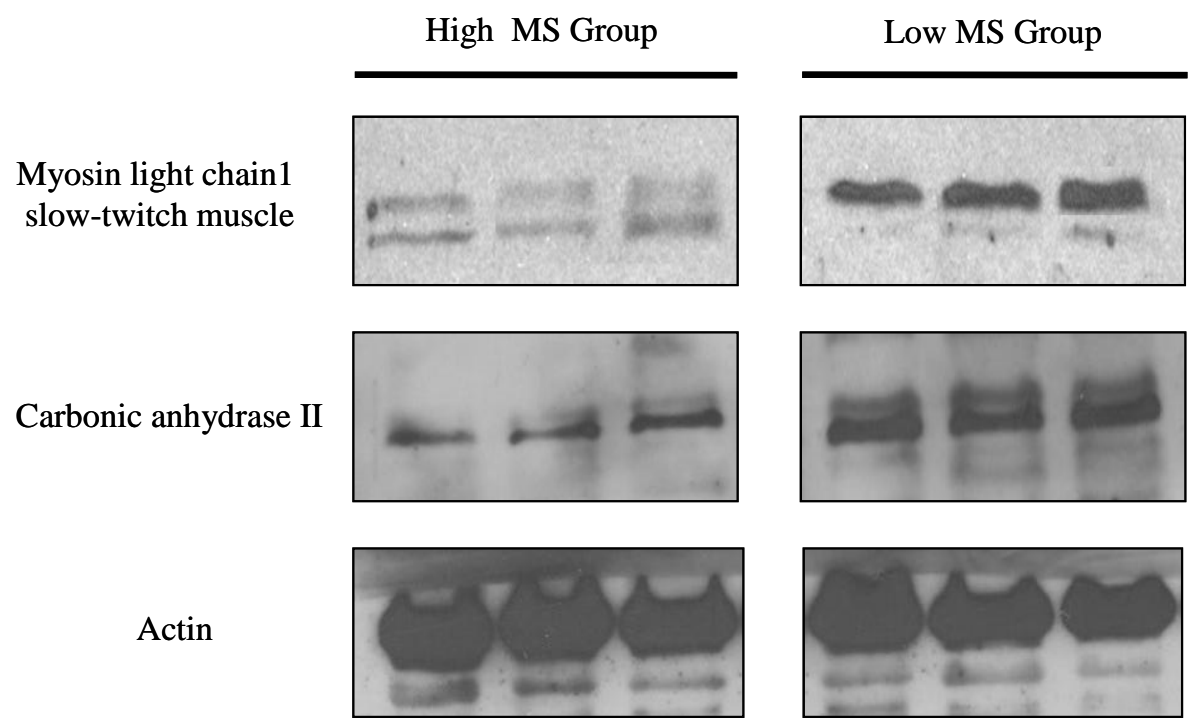

Figure 2. Expression of proteins identified in bovine longissimus dorsi tissue. Proteins were extracted from three representative samples from both groups. The expression of myosin light chain 1 and carbonic anhydrase 2 was assessed by Western blot analysis. Actin was used as a loading control.

Type I fibers have higher levels of oxidative metabolism than type II fiber (Ashmore et al., 1972; Solomon et al., 1986). In general, the glycolytic pathway in longissimus dorsi is more developed compared to other tissues such as rump. Bovine longissimus dorsi muscles were previously analyzed and found to contain 17 to $25 \%$ of type I fibers (Vestergaard et al., 2000; Therkildsen et al., 2002). This fiber is generally associated with oxidative phosphorylation (Hocquette et al., 1998; Brandstetter et al., 2002). Abundant fast-twitch fibers are thought to have a high potential for ATP production through anaerobic pathways (Gleeson, 1983; Takekura and Yoshioka, 1987). In high MS muscle, increased expression of glycolytic enzymes could be linked to reduced oxidative and increased anaerobic capacities, which would be consistent with the previously reported increase in the ratio of type II-to-type I fibers and volume density in the muscle (Kichofer et al., 2002; Kim et al., 2005). Differential expression of metabolic enzymes is essential for the functional diversity of muscle fiber types. Therefore, it was suggesting that high MS muscle contains an overall low proportion of type I (slow-twitch oxidative) fibers that enhance intramuscular fat content as an energy source.

The intensity of spot no. 5, identified as carbonic anhydrase 2 (CA2), was increased in the bovine low MS group compared to the high MS group. It is well known that CA2 is present at a high concentration in the cytoplasm of type I skeletal muscle cells and stimulates in the rate of ATP synthesis by facilitating the rapid conversion of glycolytic intermediates into oxaloacetate and citrate (Chegwidden et al., 2000). Our study also showed that the low MS group had a relatively high level of carbonic anhydrase to stimulate energy metabolism.

In conclusion, by proteomic analysis we identified a number of proteins that may act as potential bioregulators which could influence the MS in bovine longissmus dorsi muscle. It will could improve the economic performance of cattle and provide useful information about the underlying the function of bovine skeletal muscle.

\section{ACKNOWLEDGEMENTS}

This work was supported by a grant from the NextGeneration BioGreen 21 Program (no. PJ0081912011), Rural Development Administration.

\section{REFERENCES}

Ashmore, C. R., G. Tompkins and L. Doerr. 1972. Postnatal development of muscle fiber types in domestic animals. J. Anim. Sci. 34:37-41.

Bouley, J., B. Meunier, C. Chambon, S. De Smet, J. F. Hocquette and B. Picard. 2005. Proteomic analysis of bovine skeletal muscle hypertrophy. Protemics 5:490-5000.

Brandstetter, A. M., H. Sauerwein, J. H. Veerkamp, Y. Geay and J. F. Hocquette. 2002. Effects of muscle type, castration, age and growth rate on H-FABP expression in bovine skeletal muscle. Livest. Prod. Sci. 75:199-208.

Cameron, P. J., M. Zembayashi, D. K. Lunt, T. Mitsuhashi, T. Matsumoto, S. Ozawa and S. B. Smith. 1994. Relationship between Japanese beef marbling standard and intramuslar lipid in the M. long-issimus thoracis of Japanese Black and American Wagyu cattle. Meat Sci. 38:361-364.

Chaze, T., J. Bouley, C. Chambon, C. Barboiron and B. Picard. 2006. Mapping of alkaline proteins in bovine skeletal muscle. Proteomics 6:2571-2575. 
Chegwidden, W. R., N. D. Carter and Y. H. Edwards. 2000. The carbonic anhydrases: new horizons. Birkhauser Verlag, Boston, USA.

Cornforth, D. P., A. L. Hecker, D. A. Cramer, A. A. Spindler and M. M. Mathias. 1980. Maturity and its relationship to muscle characteristics of cattle. J. Anim. Sci. 50:75-80.

Crouse, J., H. Croos and S. Seidemen. 1984. Effects of a grass or grain diet on the qualityof three beef muscles. J. Anim. Sci. 58: 619-625.

Dubowitz, V. 1960. A comparative histochemical study of oxidative enzyme and phosphorylase activity in skeletal muscle. Histochemie 2:105-117.

Glass, D. J. 2003. Skeletal muscle hypertrophy and atrophy signaling pathways. Int. J. Biochem. Cell Biol. 37:1974-1984.

Gleeson, T. T. 1983. A histochemical and enzymatic study of the muscle fiber types in the water monitor, Varanus salvator. J. Exp. Zool. 227:191-201.

Hocquette, J. F., I. Ortigues-Marty, D. W. Pethick, P. Herpin and X. Fernandez. 1998. Nutritional and hormonal regulation of energy metabolism in skeletal muscles of meat-producing animals. Livest. Prod. Sci. 56:115-143.

Jeukendrup, A. E. 2002. Regulation of fat metabolism in skeletal muscle. Ann N.Y. Acad. Sci. 967:217-235.

Kichofer, K. S., C. R. Calkins and B. L. Gwartney. 2002. Fibertype composition of muscles of the beef chuck and round. J. Anim. Sci. 80:2872-2878.

Kim, S. M., M. Y. Park, K. S. Seo, D. H. Yoon, H. G. Lee, Y. J. Choi and S. H. Kim. 2006. Analysis of differentially expressed proteins in bovine longissium dorsi and biceps femoris muscles. Asian-Aust. J. Anim. Sci. 19:1496-1502.

Lametsch, R., A. Karlsson, K. Rosenvold, H. J. Andersen, P. Roepstorff and E. Bendixen. 2003. Postmortem proteome changes of porcine muscle related to tenderness. J. Agric. Food Chem. 51:6992-6997.
Larzul, C., L. Lefaucheur, P. Ecolan, J. Gogue, A. Talmant, P. Sellier, P. Le Roy and G. Monin. 1997. Phenotypic and genetic parameters for longissimus muscle fiber characteristics in relation to growth, carcass, and meat quality traits in large white pigs. J. Anim. Sci. 75:3126-3137.

Lee, D. H. 2004. Methods for genetic parameter estimations of carcass weight, longissimus muscle area and marbling score in Korean cattle. Kor. J. Anim. Sci. Technol. 46:509-516.

Moon, S. S., H. S. Yang, G. B. Park and S. T. Joo. 2006. The relationship of physiological maturity and marbling judged according to Korean grading system to meat quality traits of Hanwoo beef females. Meat Sci. 74:516-521.

Nader, G. A., T. A. Hornberger and K. A. Esser. 2002. Translational control: implications for skeletal muscle hypertrophy. Clin. Orthop. Relat. Res. 403:S178-187.

Pearson, A. M. and R. B. Young. 1989. Muscle and meat biochemistry, Academic press, San Diego. CA, USA.

Rieder, S. V. and I. A. Rose. 1959. The mechanism of the triosephosphate isomerase reaction. J. Biol. Chem. 234:10071010.

Solomon, M. B., R. L. West and J. F. Hentges. 1986. Growth and muscle development characteristics of purebred Angus and Brahman bulls. Growth 50:51-67.

Takekura, H. and Y. J. Yoshioka. 1987. Determination of metabolic profiles on single muscle fibres of different types. J. Muscles Res. Cell Motil. 8:342-348.

Therkildsen, M., L. M. Larsen and M. Vestergaard. 2002. Growth, development and meat science - Influence of growth rate and muscle type on muscle fibre type characteristics, protein synthesis capacity. Anim. Sci. 54:243-252.

Vestergaard, M., N. Oksbjerg and P. Henckel. 2000. Influence of feeding intensity, grazing and finishing feeding on muscle fibre characteristics and meat colour of semitendinosus, longissimus and supraspinatus muscles of young bulls. Meat Sci. 54:177-185.

Zierath, J. R. 1995. In vitro studies of human skeletal muscle: hormonal and metabolic regulation of glucose transport. Acta Physiol. Scand. 626:1-96. 